\title{
Social media marketing: Who is watching the watchers?
}

Jenna Jacobson ${ }^{a}$, Anatoliy Gruzd ${ }^{b}$, A. Ángel Hernández-Garcia ${ }^{c}$

\author{
a Ryerson University, Ted Rogers School of Retail Management, 350 Victoria Street, Toronto, Ontario, \\ Canada M5B 2K3 \\ ${ }^{\mathrm{b}}$ Ryerson University, Ted Rogers School of Information Technology Management, 350 Victoria Street, \\ Toronto, Ontario, Canada M5B 2K3 \\ ${ }^{\mathrm{c}}$ Universidad Politécnica de Madrid, Department of Organization Engineering, Business Administration \\ and Statistics, Av. Complutense, 30, 28040 Madrid, Spain
}

Keywords: Digital marketing; Ethics; Social media; Consumer trust; Privacy

\begin{abstract}
The ready access to and availability of social media has opened up a wealth of data that marketers are leveraging for strategic insight and digital marketing. Yet there is a lack of professional norms regarding the use of social media in marketing and a gap in understanding consumers' comfort with marketers' use of their social media data. This study analyzes a census-balanced sample of online adults $(n=751)$ to identify consumers' perceptions of using social media data for marketing purposes. The research finds that consumers' perceived risks and benefits of using social media have a relationship with their comfort with marketers using their publicly available social media data. The research extends the applicability of communication privacy management theory to social media and introduces marketing comfort - a new construct of high importance for future marketing research. Marketing comfort refers to an individual's comfort with the use of information posted publicly on social media for targeted advertising, customer relations, and opinion mining. In the context of the construct development, we find that targeted advertising is the strongest contributing component to marketing comfort, relative to the other two dimensions: opinion mining and customer relations. By understanding what drives consumer comfort with this emerging marketing practice, the research proposes strategies for marketers that can support and mitigate consumers' concerns so that consumers can maintain trust in marketers' digital practices.
\end{abstract}

\section{Introduction}

Just as the use of social media is changing how people live (Quan-Haase \& Young, 2010), learn (Gruzd, Paulin, \& Haythornthwaite, 2016), and connect with one another (van Dijck, 2012), fundamental shifts are also taking place within businesses with the introduction and use of social media. Consumers are using social media to generate information and share their experiences with their friends, companies, and broader online communities via posts, tweets, shares, likes, and reviews (Bailey, Bonifield, \& Arias, 2018; Dimitriu \& Guesalaga, 2017; Martín-Consuegra, Díaz, Gómez, \& Molina, 2018). Businesses are taking notice as they adopt strategies and tools to engage in social media listening (Misirlis \& Vlachopoulou, 2018; Schweidel \& Moe, 2014). From a design retailer combining social media and predictive analytics to gather sentiment on potential new 
products (Amato-McCoy, 2018) to travel companies mining unstructured social media data to present users with personalized offers (Western Digital, 2018), marketers are particularly interested in understanding what their customers and the public are saying about their business (Tuten \& Solomon, 2017).

While social media listening has been shown to be extremely valuable for businesses to better understand what their customers and the public are saying about their products or services (Lee, 2018; Paniagua \& Sapena, 2014), not all consumers might be comfortable with such practices (Akar, \& Topçu, 2011; Dubois, Gruzd \& Jacobson, 2018). And if they are not comfortable with what and how marketers use social media data, consumers may develop negative attitudes, which may in turn impact consumers' purchasing intention and lead to a loss of trust and a damaged relationship between the consumer and the company (Adjei, Noble, \& Noble, 2010; Arnold, 2018; Goldfarb \& Tucker, 2013). For example, when a UK-based insurance company decided to rely on Facebook posts to price car insurance, it created a backlash in the form of negative publicity about the company and their data practice (Ruddick, 2016). In addition, recent data breaches at Facebook and the platform's secretive data sharing arrangements with other tech giants (Dance, LaForgia, \& Confessore, 2018; Kanter, 2018) have heightened people's privacy concerns and increased their awareness of who might be accessing their data and for what purposes (Cochrane, 2018; DMA, 2018a, b). These recent cases highlight the need for developing a more granular understanding of consumers' attitudes towards marketers' use of their social media data. Prior research has primarily focused on the organizational environment and personal characteristics of marketers or decision makers in marketing professions (Singhapakdi, Vitell, \& Kraft, 1996). While the perspective of marketers is important to understand the professional practices, there is little knowledge about the public's attitudes towards marketers using their social media data, which we seek to address in this study.

A unique aspect of our work is that we study people's attitudes towards the use of publicly accessible social media data. While data breaches (like in the cases mentioned above) do happen, typically marketers would not have direct access to users' data that is privately shared with a selected group of friends or shared in members-only online groups - at least, not without users' consent. But the situation is different when it comes to user-generated content shared publicly on social media, such as a public post on Twitter or a comment in a public Facebook page. Because of their business models, most major social media platforms encourage data use for marketing purposes through well-developed APIs (data sharing protocols) and an ecosystem of third-party applications that rely on APIs to offer business intelligence services. Furthermore, few jurisdictions around the world have regulations in place to limit or make these data mining practices more transparent - with some exceptions like the General Data Protection Regulation in the European Union. We argue that even if data access and use is possible and legal, marketing professionals have ethical responsibilities that extend beyond the legal requirements.

In this context, this study seeks to help marketing professionals develop strong professional principles and guidelines while still being able to benefit from many opportunities that social media has to offer to both sides: consumers and businesses. We achieve this goal by examining 
relationships between consumers' information privacy concerns, social media use gratifications, and self-disclosure practices with their comfort with marketers using their social media data. By understanding what drives consumers' comfort with these emerging data practices, we propose strategies for marketers that can support and mitigate consumers' discomfort with social media data use. Beyond the practical reasons, the research is also important because of the evolving marketing ethics. While marketers have always had to grapple with various ethical considerations in their practices, the widespread adoption and use of the internet has introduced new challenges for implementing marketing ethics (Laczniak \& Murphy, 2006). The research addresses the link between marketing ethics and consumer comfort with emergent marketing practices by introducing a new construct: marketing comfort. As a theoretical lens, the research is guided by communication privacy management. While communication privacy management (CPM) theory has been applied to marketing ethics, we extend CPM and assess its applicability in the context of publicly available social media data.

In the following, we outline the: (1) relevant literature on social media marketing and ethics in marketing, (2) use of Petronio's Communication Privacy Management theory to guide the research and the three hypotheses, (3) methods and data analysis, (4) results of the data analysis, (5) discussion, and (6) conclusions including the limitations and implications of the research.

\section{Literature review}

\subsection{Social media marketing}

Social media marketing is used across sectors and refers to "the utilization of social media technologies, channels, and software to create, communicate, deliver, and exchange offerings that have value for an organization's stakeholders" (Tuten \& Solomon, 2017, p. 18). In a systematic review of the social media literature, Kapoor et al. (2018) find that social media has been widely adopted as a marketing medium. In the private sector, social media is often used as a communication tool to promote and sell products and services; in the public sector, social media is often used to share information and encourage user engagement (Royle \& Laing, 2014; Gruzd, Jacobson, Mai \& Dubois, 2018a). Beyond being another medium to communicate with one's audience, social media affords the opportunity for social and professional relationships to be built, sustained, and strengthened with friends, family, and even businesses. Marketers employ relationship marketing strategies to build long-term relations that are mutually satisfying with key parties, including customers (Kang \& Kim, 2017; Murphy, Laczniak, \& Wood, 2007; Kamboj, Sarmah, Gupta, \& Dwivedi, 2018; for a systematic literature review of social media marketing see: Alalwan, Rana, Dwivedi \& Algharabat, 2017; Misirlis \& Vlachopoulou, 2018; Felix, Rauschnabel, \& Hinsch, 2017).

Research has analyzed the effectiveness of social media marketing (Dwivedi, Kapoor, \& Chen, 2015; Kapoor et al., 2018; Lee \& Hong, 2016) and behavioural attitudes towards viral marketing (Citton, 2017; Eppler \& Mengis, 2004) and advertising (Alalwan, 2018; Lee \& Hong, 2016; Shareef, Mukerji, Alryalat, Wright, \& Dwivedi, 2018; Shareef, Mukerji, Dwivedi, Rana, \& Islam, 2019). Factors such as interactivity (Jiang et al., 2010), perceived relevance (Jung, 2017), perceived usefulness (Chang, Hung, Cheng, \& Wu, 2015), and organizational reputation (Boateng 
\& Okoe, 2015) have been found to impact consumers' attitudes towards social media marketing. Put simply, Alalwan (2018) explains, "customers who find social media advertising beneficial and more advantageous are more likely to be willing to purchase the targeted products of these ads" (p. 73).

Marketers are using publicly available social media data for three common functions: opinion mining, targeted advertising, and customer relations. First, marketers engage in opinion mining, which involves leveraging the plethora of social media data to uncover knowledge, insights, and patterns derived from structured and unstructured data (He, Zha, \& Li, 2013). Opinion mining may also involve tracking mentions or particular phrases (Tuten \& Solomon, 2017). Marketers then extract actionable patterns that can be used to reach their strategic business goals and provide a competitive edge in the marketplace (Gundecha \& Liu, 2012).

Second, the use of social media in marketing has contributed to the individualization of marketing whereby organizations can communicate, collect data, and provide personalized responses and solutions for customers (Royle \& Laing, 2014; Simmons, 2008). Marketers can therefore leverage social media to craft personalized messages and offers for target audiences (Sterne, 2010). Personalized offers may deliver five to eight times the return on investment (ROI) on marketing expenditure and can increase sales by more than 10\% (Cochrane, 2018).

Third, developing strong relationships with customers is the main objective of marketing programs (Soler-Labajos \& Jimenez-Zarco, 2016) and customer relations are improved using social media (Ainin, et al., 2015). As a tool for customer relations, social media is used to attract customers with user-generated content, engage customers using online two-way social interactions, and retain customers through building relationships with other members (Wang \& Fesenmaier, 2004). A key part of effective customer relations is delivering pertinent information at the correct time and forming a personalized connection with the customer (Peppers \& Rogers, 2017). Traditional customer relationship management (CRM) databases include personal information about the customers and are now being augmented with social CRM derived from social media data to obtain more detailed personal information (Soler-Labajos \& Jimenez-Zarco, 2016). Businesses can add value to the customer experience by better understanding the wants and needs of the customer.

In this study we focus on three common functions of using social media data for marketing: (1) extracting insights via opinion mining, (2) delivering information via targeted advertising, and (3) communicating via customer relations with new or existing customers (Boerman, Kruikemeier, \& Borgesius, 2017; Liu, Burns, \& Hou, 2017; Malthouse \& Li, 2017; Sheng, Amankwah-Amoah, $\&$ Wang, 2018). These functions speak to the three different informational exchanges: pulling (i.e. opinion mining), pushing (i.e. targeted advertising), and exchanging (i.e. customer relations). Opinion mining involves natural language processing to identify the audience's overall mood about a particular topic; for example, marketers can use opinion mining to determine the success of a marketing campaign as well as what is or is not working well for customers (Vinodhini \& Chandrasekaran, 2012). Targeted advertising refers to the segmentation of the population into subgroups based on user preferences and then the delivery of advertisements for products and 
services that the subgroup will find desirable (Yang, Dia, Cheng, \& Lin, 2006); marketers use social media as the data source to algorithmically group users and deliver more personalized advertisements. Finally, customer relations refer to the relationship an organization has with its customers and is hailed "the new marketing" due to the customer's ability to share their issues on social media (Kietzmann, 2011); marketers can then use social media to build and foster relationships with consumers.

In the internet era, the possibility of collecting massive amounts of personal consumer data has caused a shift in consumers' privacy concerns (Goldfarb \& Tucker, 2013), which has critical implications for evaluating the ethical practices in marketing, as discussed in the following section.

\subsection{Ethics in marketing}

Social media is celebrated as giving people the opportunity to express themselves and their ideas via user-generated content (van Dijck, 2009), yet many people express privacy concerns with the use of their social media data by third parties (Acquisti \& Gross, 2006; Gruzd \& HernandezGarcia, 2018; Gruzd, Jacobson, Mai \& Dubois, 2018b; Marwick \& Hargittai, 2018). In the current marketing communities, there are scholarly debates surrounding ethics, including normative ethics (what should be), positive ethics (what is or could be), consumer ethics (what moral rules guide consumers), and virtue ethics (what is ethical) approach (Hunt \& Vitell, 1986, 2006; Murphy, Laczniak, \& Wood, 2007; Vitell, 2003). Unlike traditional marketing, which involves a one-way dissemination of information, the use of the internet affords two-way communication that poses different ethical and privacy considerations for marketers (Malhotra, Kim, \& Agarwal, 2004). Even with publicly available social media data, individuals may still have expectations of privacy (Gruzd \& Hernandez-Garcia, 2018; Gruzd, Jacobson, Mai \& Dubois, 2018b). Serious privacy and ethical considerations are raised when organizations seek to capitalize on the wealth of data from social media and the internet more broadly (Malhotra, Kim, \& Agarwal, 2004; Ward, 2018).

Previous research has sought to explore how marketers come to make ethical decisions based on personal characteristics (Singhapakdi, Vitell, \& Kraft, 1996). Hunt and Vittell (1986) contend that people respond differently to ethical questions or situations because of their ethical sensitivity. Sparks and Hunt (1998) find that when marketing professionals are placed in a decision-making situation, many marketers will fail to recognize the ethical issues, which is even more complicated as marketers explore opportunities to leverage social media data. Regarding social media marketing, Barger, Peltier, and Schultz (2016) argue that there is fragmentation in the discipline and call for further research to understand how consumer engagement can be embraced for the benefit of consumers and companies.

While understanding the decision-making process of marketing professionals provides insight into what "is" the current state of social media marketing, it does not contribute to an understanding of what marketing ethics of using social media data "ought" to be. As Malhotra and Miller (1998) state, "Remembering that the consumer is an essential part of the marketing process cannot be ignored, it seems that more energy should be devoted towards targeting efforts to the consumer (client, respondents, and public) perspective of ethical dilemmas in marketing research, 
rather than solely through the eyes of the business (researcher)" (p. 271). Thus, understanding the consumer perspective on marketers' use of social media data needs to be considered.

\section{Theoretical framework and hypotheses}

With the focus on consumers, we turn to Petronio's (2002) Communication Privacy Management (CPM) theory that explores how people regulate information they consider to be private. At its core, the theory describes how individuals develop their own privacy rules to calculate the risks and benefits of disclosing information. The theory contends that privacy management is dialectic in that people need to disclose private information to fulfill social functions and needs, while also concealing information to maintain their protection (Baruh, Secinti, \& Cemalcilar, 2017). In recent years, CPM has been widely adopted by scholars examining information privacy concerns in the context of social media use (e.g., Cavusoglu, Phan, Cavusoglu, \& Airoldi, 2016; Child, Haridakis, \& Petronio, 2012; DeGroot \& Vik, 2017; Waters \& Ackerman, 2011).

Businesses may be overestimating not just consumers' comfort with sharing their personal data, but also the extent to which they feel they receive fair value in exchange (Conroy, Milano, Narula, \& Singhal, 2014). By applying the CPM theory, this study explores the tension between users' information privacy concerns (Alashoor, Han, \& Joseph, 2017; Bellman et al., 2004; Hazari \& Brown, 2013; Proudfoot, Wilson, Valacich, \& Byrd, 2018) and the benefits associated with social media use - such as supporting self-presentation, social relationships, entertainment, and information sharing (Blatterer, 2010; Debatin, Lovejoy, Horn, \& Hughes, 2009; Fox \& Moreland, 2015; Quinn, 2016; Sundar \& Limperos, 2013). Importantly, we examine this tension in relation to people's attitudes towards marketers using their publicly available social media data; thus, we hypothesize:

H1: Consumers' perceived risks of using social media have a negative relation with the comfort with marketers using their publicly available social media data.

H2: Consumers' perceived benefits of using social media have a positive relation with the comfort with marketers using their publicly available social media data.

While considering both risks and benefits of being social, consumers may engage in various information privacy protective responses (IPPR), such as posting less often or posting less accurate information (Das \& Kramer, 2013; Gruzd \& Hernandez-Garcia,, 2018; Hayes, Glynn, \& Shanahan, 2005; Son \& Kim, 2008). From the CPM theory perspective, IPPR can be viewed as a mechanism to manage one's privacy boundaries (Jeong \& Kim, 2017). Petronio (2002) theorizes that individuals set their privacy boundaries from completely open to completely closed. One way to engage in IPPR - and to assess one's privacy boundaries - is to measure the amount, depth, intent, polarity, and accuracy of one's self-disclosure on social media (Gruzd \& Hernandez-Garcia, 2018). Our expectation is that open boundary individuals may be more comfortable with marketers using their publicly available social media data; thus, we hypothesize: 
H3: Consumers' self-disclosure practices on social media have a positive relation with the comfort with marketers using their publicly available social media data.

\section{Method}

\subsection{Data collection}

The research hypotheses were tested with data from a cross-national survey based on the internet panel hosted by Research Now. Research Now has been used by academic researchers to access panels of individuals based on specific criteria or as a representative sample of the general population (Finucane, Slovic, Mertz, Flynn, \& Satterfield, 2000; Freelon, Watanabe, Busch, \& Kawabata, 2008; Giles et al., 2016; Zmud, Sener, \& Wagner, 2016). The survey design was piloted and refined over a one-year period. The broad research goal of the survey was to understand individuals' social media use, privacy concerns, and comfort with third parties mining their publicly available information on social media. Aligned with Research Now's typical protocol, participants were given eRewards, which are points that can be transferred to various loyalty rewards programs, upon completion. The research proposal was approved by the university's Research Ethics Board in Canada.

The use of an online panel does not bias the survey results because the survey solely focuses on internet users. Quota sampling was used to align with the demographics of the Canadian population to increase the representativeness of the data; participants were screened to match the distributions in the 2016 Statistics Canada Census ${ }^{1}$ report including age (at least 18 years old), gender ${ }^{2}$, and location. Participants that met the quota sampling requirements were shown a consent form that described the purpose, outlined what participants were being asked to do and estimated time of completion, defined potential benefits and risks, assured anonymity, outlined data protection and storage processes, described incentives, identified rights of research participants, and provided contact information for the research team. All data was anonymized and is presented in aggregate.

The online survey was hosted by Qualtrics and was open from June 1, 2017 to July 15, 2017. We engaged in active data cleaning throughout the collection process and we ceased data collection once we reached our target of 1500 completed respondents. We systematically excluded responses that did not answer the "trap question" correctly to ensure high quality responses. The survey had a median completion time of $17 \mathrm{~min}$ and $16 \mathrm{~s}$. This research analyzes a subset of people $(n=751)$ who have at least one public social media account considering this is the data available to third parties (i.e. marketers). Table 1 shows the demographic and social media characteristics of the sample used in this study. The sample is balanced across different age groups, but has slightly more women than men (52\% vs $48 \%)$.

\footnotetext{
1 The market research company used for data collection, unfortunately, does not include access to panel survey participants in Yukon, Northwest Territories, and Nunavut.

2 The authors would like to acknowledge that we recognize gender is not binary. The screening question is aligned with Statistics Canada's demographic questions to recruit a representative sample for statistical analysis. Later in the survey, participants were given the opportunity to respond to a more inclusive question regarding gender.
} 
Table 1: Sample Demographics

\begin{tabular}{|c|c|c|c|c|c|c|c|c|c|c|c|c|c|c|}
\hline Demographic & Category & $\mathrm{N}$ & Percentage & $\begin{array}{l}\text { Cumulative } \\
\text { percentage }\end{array}$ & 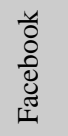 & 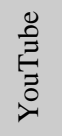 & 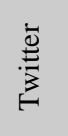 & 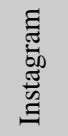 & 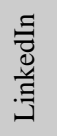 & $\begin{array}{l}\overrightarrow{\tilde{D}} \\
\stackrel{0}{0} \\
\stackrel{0}{\Xi}\end{array}$ & 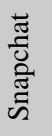 & 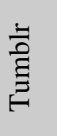 & 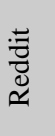 & $\frac{00}{0}$ \\
\hline \multirow{2}{*}{ Gender } & Female & 391 & $52.1 \%$ & $52.1 \%$ & 97 & 121 & 160 & 129 & 155 & 181 & 32 & 66 & 26 & 56 \\
\hline & Male & 360 & $47.9 \%$ & $100.0 \%$ & 135 & 160 & 139 & 75 & 164 & 48 & 29 & 16 & 33 & 50 \\
\hline \multirow{6}{*}{ Age } & Under 25 & 130 & $17.3 \%$ & $17.3 \%$ & 23 & 57 & 60 & 51 & 37 & 37 & 19 & 46 & 24 & 18 \\
\hline & $25-34$ & 154 & $20.5 \%$ & $37.8 \%$ & 28 & 60 & 74 & 63 & 71 & 64 & 22 & 19 & 16 & 25 \\
\hline & $35-44$ & 134 & $17.8 \%$ & $55.7 \%$ & 34 & 54 & 57 & 37 & 65 & 39 & 10 & 6 & 10 & 20 \\
\hline & $45-54$ & 125 & $16.6 \%$ & $72.3 \%$ & 50 & 43 & 51 & 27 & 59 & 30 & 5 & 3 & 6 & 13 \\
\hline & $55+$ & 208 & $27.7 \%$ & $100.0 \%$ & 97 & 67 & 57 & 26 & 87 & 59 & 5 & 8 & 3 & 30 \\
\hline & Total & 751 & $100.0 \%$ & $100.0 \%$ & 232 & 281 & 299 & 204 & 319 & 229 & 61 & 82 & 59 & 106 \\
\hline
\end{tabular}

The research asks participants about "publicly available social media data," which refers to information posted by the user or about the user by other people across platforms, for three reasons. First, even if an individual does not have a social media account on a particular platform, they can still be targeted; social media platforms create "shadow profiles" of individuals who do not have an account on the platform, yet have data about the individual from their social contacts. Second, marketers can scrape publicly available data from various social networks and are able to aggregate the data for marketing purposes. Finally, marketing messages are shown across platforms using cookies. While we recognize that people use specific social media platforms for different reasons and get different gratifications, for the purposes of this study, publicly available data needs to be understood in aggregate.

The survey asked respondents to indicate whether each of their social media accounts were primarily public or private. The reason the word "primarily" was used in these questions is because users can maintain a public account while also restricting access to few items in their profile to a selected group of users; or in the opposite case, a user can have a restricted account with few items shared with a wider audience.

\subsection{Instrument design}

Derived from the theoretical framework, the research defines the three predicting variablesInformation Privacy Concerns, Gratification, and Self-Disclosure - as multidimensional, secondorder reflective-formative latent variables. The instruments and scales for each construct have been validated by prior research. The target endogenous construct, marketing comfort, is defined as a formative composite and captures the three elements detailed in the literature review and theoretical framework: comfort with the use of information posted publicly on social media for targeted advertising, customer relations, and opinion mining.

To measure privacy concerns, following Stewart and Segars (2002), the Concerns for Information Privacy (CFIP) instrument assesses one's concerns for information privacy in response to an organization's use or potential use of their personal information across four dimensions: collection (COL), errors (ERR), secondary use (SUS), and unauthorized access 
(UAC). The research follows the Concern for Social Media Information Privacy (CFSMIP) instrument developed by Osatuyi (2015) to support sharing information on social media.

Following Cheung, Lee, and Chan (2015), we assess the Gratification (GRAT) of social media based on the following four dimensions: Information Sharing ${ }^{3}$ (G-INF), New Relationship Building (G-SOC), Self-Presentation (G-SP), and Enjoyment (G-Ent).

Finally, self-disclosure captures four different dimensions (Lai \& Yang, 2015; Leung, 2002): (1) Amount and Depth (SDAD): how much information people disclose on social media and to what extent people reveal their personal and intimate information about themselves; (2) Positive/Negative Valence or Polarity (SDPN): to what extent their online disclosures show their most positive and desirable self-image; (3) Accuracy (SDAc): the level of honesty and accuracy in one's disclosures; and (4) Intention (SDI): whether people are fully aware of their disclosures on social media. The items, originally proposed by Wheeless $(1976,1978)$, were modified to fit the social media use context (Lai \& Yang, 2015). The final items included in the research were previously used in the refined instrument for self-disclosure by Gruzd \& Hernandez-Garcia (2018).

Some scales were reversed to better interpret the results; in particular, CFSMIP: from strongly agree (higher concerns) to strongly disagree, GRAT: from strongly agree (higher gratification) to disagree, Self-Disclosure: from strongly agree (higher levels of disclosure) to strongly disagree (lower levels of disclosure), and marketing comfort: from extremely comfortable to extremely uncomfortable (see Appendix 1).

\subsection{Data analysis}

To test the research model, the study uses Partial Least Squares Structural Equation Modeling (PLS-SEM), a non-parametric method. PLS-SEM is an appropriate technique when the research goal is to predict key target products or identify key driver products in complex models that include formatively measured constructs (Hair, Hult, Ringle, \& Sarstedt, 2017). The analysis follows the recommendations of Hair, Hult, Ringle, and Sarstedt (2017) for the application of PLS-SEM, and Hair, Sarstedt, Ringle, and Gundegan (2018) for assessment of hierarchical component models in PLS-SEM. According to these recommendations, the analysis includes a measurement model assessment — of both reflective and formative variables — and structural model assessment using factor weighing scheme.

\section{Measurement model assessment}

Internal reliability was tested by observing composite reliability $\left(\rho_{c}\right)$, with all values higher than 0.85 , well above 0.6 . All factorial loadings of the reflective indicators were above the cut-off level of 0.708. Convergent validity was confirmed upon observation of AVE values, which were over the threshold of 0.5. As mentioned before, measurement of the second-order variables proposed a reflective-formative approach using Mode A for the higher order construct (Hair, Sarstedt, Ringle, \& Gudergan, 2018). Regarding marketing comfort, defined formative, after discarding potential

${ }^{3}$ Cheung, Lee, and Chan (2015) refer to this dimension as "Convenience of Maintaining Existing Relationships." 
multicollinearity issues upon observation of the VIF values, a bootstrapping procedure with 5000 subsamples shows that both comfort with the use of social media data for targeted advertising and for customer relations are significant, with outer weights of comfort with the use of information posted on social media for opinion mining being not significant $(p=0.06)$; however, the outer loading of comfort with the use of personal social media data for opinion mining has a significant outer loading of 0.82 ( $\mathrm{p}<0.001)$. This means that the indicator should be interpreted as absolutely important for the measurement of marketing comfort, but relatively important when compared to the other two indicators, and thus is retained for the analysis. Appendix 2 and Appendix 3 summarize the results of internal consistency and convergent validity analyses.

Discriminant validity was assessed using the HTMT criterion (Henseler, Ringle, \& Sarstedt, 2015) (see Table 2 and Table 3). The results confirm discriminant validity between firstorder constructs and between second-order constructs as all values are lower than 0.85. There is one exception: the heterotrait-monotrait ratio of correlations between secondary use and unauthorized access yields a value of 0.88 . This result is aligned with the findings of Osatuyi (2015) and Gruzd \& Hernandez-Garcia (2018). Considering that the value was lower than the less restrictive limit of 0.90 , and to preserve content validity, both variables were kept independent.

Table 2: Discriminant Validity Assessment: HTMT (first-order constructs)

\begin{tabular}{|l|c|c|c|c|c|c|c|c|c|c|c|}
\hline \multicolumn{2}{|l}{ Heterotrait-monotrait ratio of correlations (HTMT) } \\
\hline & COL & ERR & SUS & UAC & SDAc & SDAD & SDPN & SDI & G-INF & G-SOC & G-SP \\
\hline COL & & & & & & & & & & & \\
\hline ERR & 0.50 & & & & & & & & & & \\
\hline SUS & 0.60 & 0.56 & & & & & & & & & \\
\hline UAC & 0.61 & 0.63 & $\mathbf{0 . 8 8}$ & & & & & & & & \\
\hline SDAc & 0.08 & 0.18 & 0.16 & 0.15 & & & & & & & \\
\hline SDAD & 0.08 & 0.09 & 0.21 & 0.17 & 0.35 & & & & & & \\
\hline SDPN & 0.06 & 0.18 & 0.14 & 0.18 & 0.64 & 0.47 & & & & & \\
\hline SDI & 0.08 & 0.21 & 0.34 & 0.35 & 0.74 & 0.15 & 0.67 & & & & \\
\hline G-INF & 0.10 & 0.08 & 0.11 & 0.13 & 0.44 & 0.28 & 0.56 & 0.38 & & & \\
\hline G-SOC & 0.08 & 0.13 & 0.03 & 0.08 & 0.35 & 0.45 & 0.45 & 0.24 & 0.68 & & \\
\hline G-SP & 0.06 & 0.11 & 0.11 & 0.14 & 0.43 & 0.30 & 0.66 & 0.42 & 0.72 & 0.71 & \\
\hline G-ENT & 0.11 & 0.05 & 0.08 & 0.13 & 0.38 & 0.27 & 0.50 & 0.35 & 0.83 & 0.68 & 0.68 \\
\hline
\end{tabular}

Table 3: Discriminant Validity Assessment: HTMT (second-order constructs)

\begin{tabular}{|l|c|c|}
\hline \multicolumn{3}{|l|}{$\begin{array}{l}\text { Heterotrait-monotrait ratio of } \\
\text { correlations (HTMT) }\end{array}$} \\
\hline & CFSMIP & SD \\
\hline CFSMIP & & \\
\hline SD & 0.24 & \\
\hline GRAT & 0.13 & 0.58 \\
\hline
\end{tabular}




\section{Results}

Analysis of the variance inflation factor (VIF) returned values below 3, which suggests that there are no multicollinearity problems in the model. The path coefficients (see Figure 1) from Information Privacy Concerns, Gratification, and Self-Disclosure, to marketing comfort are -0.19, 0.30 , and 0.14 respectively - all significant at $\mathrm{p}<0.01$, after a bootstrapping procedure with 5000 subsamples. The value of $\mathrm{R}^{2}$ for the new construct, marketing comfort, is 0.18 ; in other words, the three predicting variables explain $18 \%$ of the variance in marketing comfort. Considering the exploratory nature of the research and that the model introduces a new concept, this value may be considered acceptable. $\mathrm{R}^{2}$ values of 0.20 may be considered high in consumer behaviour disciplines, even though they may be considered moderate to weak for other marketing issues in success driver studies (Hair, Hult, Ringle, \& Sarstedt, 2017; Hair, Hollingsworth, Randolph, \& Loong Chong, 2017). The $\mathrm{R}^{2}$ value suggests low predictive accuracy of the model, which might be partially explained by the high number of responses expressing extreme discomfort with the use of social media data for marketing purposes, and also the strong positions about privacy concerns regarding unauthorized access and secondary use of the information. The inclusion of additional variables, which will be discussed in the following section, could help to increase the predictive power of the model. However, and regardless of proportion of variance explained, the results of the analysis of the structural model confirm the significance of the hypothesized relations. The observation of the $f^{2}$ effect sizes shows that self-disclosure has a negligible effect $\left(f^{2}\right.$ $=0.02)$ with a higher, yet small, effect of privacy concerns $\left(f^{2}=0.04\right)$ and gratification $\left(f^{2}=0.08\right)$. The blindfolding procedure with a distance omission of 7 returns positive values of $\mathrm{Q}^{2}$, which confirms the predictive relevance of the model; however, observation of the $q^{2}$ values unveil the negligible predictive relevance of self-disclosure $\left(q^{2}=0.01\right)$ and confirm the predictive relevance, even though small, of privacy concerns $\left(q^{2}=0.03\right)$ and gratification $\left(q^{2}=0.05\right)$.

Aligned with the CPM theory, all three hypotheses are supported, which suggests that consumers are actively engaged in the assessment of risks and benefits when forming their attitudes towards the practice of marketers using the public's social media data - with gratification being the strongest predictor of comfort. In accordance with $\mathrm{H} 3$, the results also confirm that individuals with more open privacy boundaries are more comfortable with this practice, but selfdisclosure only accounted for an additional $1.3 \%$ of the variance explained in marketing comfort, suggesting that user behaviour (self-disclosure practices) by itself should not be used to determine one's comfort with the studied practice.

Overall, while the majority of respondents were not comfortable with marketers' use of publicly available social media data (see Table 4), the findings also suggest that social media users are not passive consumers of advertisements. Individuals are actively assessing risks and benefits, which supports the use of CPM theory in the context of social media data and marketing, with targeted advertising being the strongest contributing dimension of marketing comfort. 
Figure 1: Results of the Structural Model Assessment

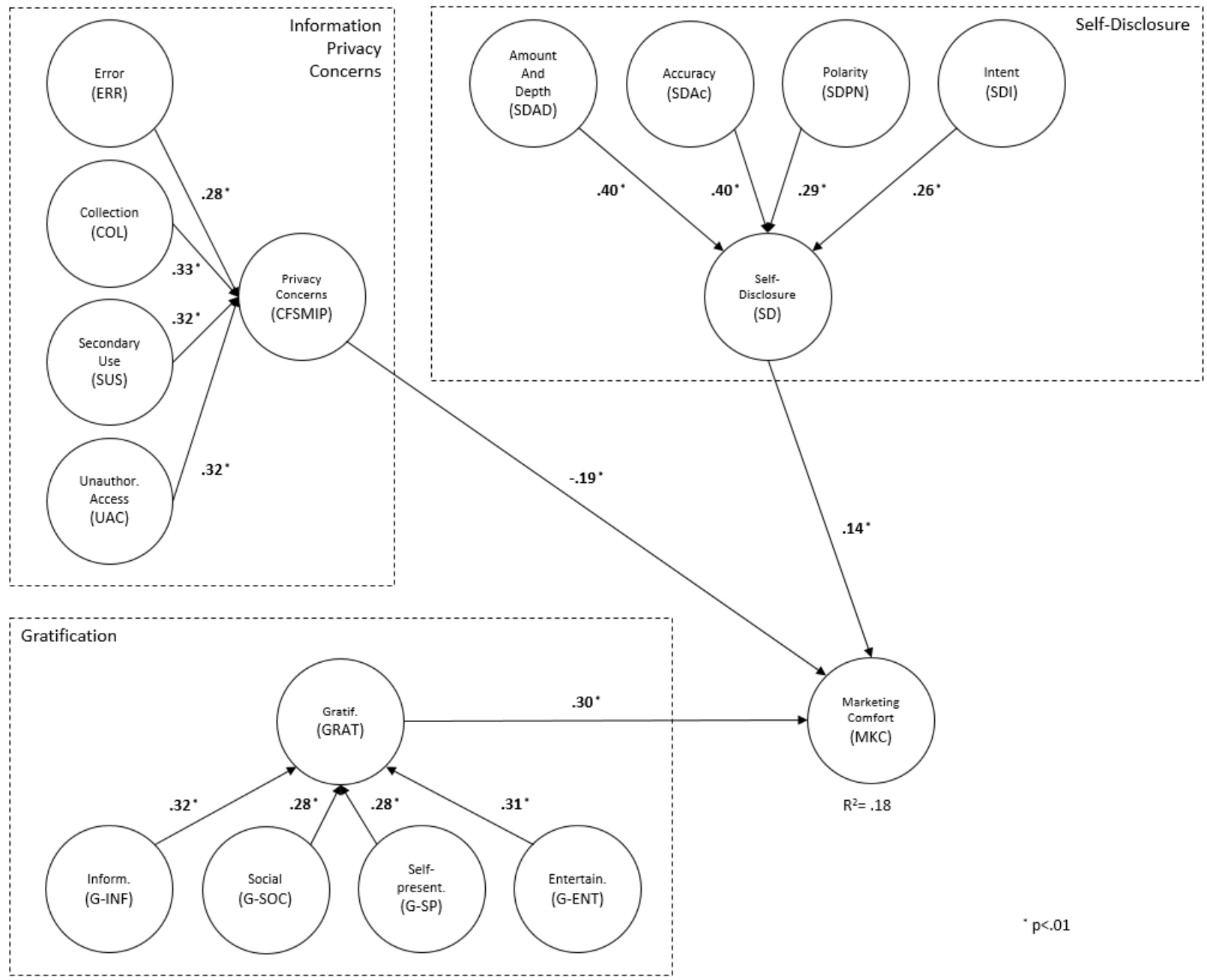

Table 4: Comfort with Marketers using Publicly Available Social Media Data

\begin{tabular}{|l|l|l|l|}
\hline Comfort Level & Targeted Ads & Opinion Mining & Customer Relations \\
\hline Extremely comfortable & $40(5.3 \%)$ & $62(8.3 \%)$ & $56(7.5 \%)$ \\
\hline Moderately comfortable & $54(7.2 \%)$ & $89(11.9 \%)$ & $86(11.5 \%)$ \\
\hline Slightly comfortable & $98(13 \%)$ & $106(14.1 \%)$ & $116(15.4 \%)$ \\
\hline $\begin{array}{l}\text { Neither comfortable } \\
\text { nor uncomfortable }\end{array}$ & $160(21.3 \%)$ & $176(23.4 \%)$ & $178(23.7 \%)$ \\
\hline Slightly uncomfortable & $125(16.6 \%)$ & $104(13.8 \%)$ & $97(12.9 \%)$ \\
\hline Moderately uncomfortable & $100(13.3 \%)$ & $88(11.7 \%)$ & $70(9.3 \%)$ \\
\hline Extremely uncomfortable & $174(23.2 \%)$ & $126(16.8 \%)$ & $148(19.7 \%)$ \\
\hline
\end{tabular}




\section{Discussion}

\subsection{Theoretical contributions}

In the marketing literature and professional practice, there is currently a lack of understanding of what the ethical norms are due to a lack of research on people's expectations of privacy and comfort with marketers using social media data. Our research fills this gap by developing a nuanced understanding of consumers' comfort with social media marketing practices. Even when marketers are using public data, consumers still have concerns about the use of their social media data: $53.1 \%, 42.3 \%$, and $41.9 \%$ are uncomfortable with marketers using their social media data for targeted advertisement, opinion mining, and customer relations respectively (see Table 4).

The research also introduces a new construct, marketing comfort, to address the link between marketing ethics and consumer comfort. Marketing comfort comprises the three main functions of using social media data for marketing purposes: pulling, pushing, and exchanging information. The study, therefore, operationalizes marketing comfort as an individual's comfort with the use of information posted publicly on social media for targeted advertising, customer relations, and opinion mining.

To identify the drivers of marketing comfort, the three research hypotheses explore the relation between information privacy concerns, uses and gratifications of social media, selfdisclosure practices in social media, and consumers' comfort with marketers using their publicly available social media data. The results further support the application of the CPM theory in the context of publicly available social media data: individuals are assessing the benefits and risks (H1 and H2) and actively managing privacy boundaries by considering what they disclose (H3). Thus, both risks and benefits play into consumer comfort, which shows the applicability of the CPM theory. Importantly, the study extends Petronio's (2002) CPM theory in the context of publicly available social media data, which is a major contribution to the literature. The results confirm that, even though people are assessing their risks with the practice, they are willing to compromise some privacy because they also derive benefits from social media use. The findings also suggest the applicability of the privacy calculus theory (Culnan \& Armstrong, 1999) to the use of social media-users make a trade-off assessment of the benefits of disclosure against their privacy concerns associated with such disclosure.

\subsection{Implications for practice}

The research joins prior scholarship that has practical implications to enhance marketing practices (Ismagilova et al., 2019; Kamboj, Sarmah, Gupta, \& Dwivedi, 2018; Shareef, Mukerji, Dwivedi, Rana, \& Islam, 2019). In particular, the study shows that while users still value using social media platforms as a source of entertainment and information - where they can express and present themselves in favorable ways - they are becoming more aware of the use of these platforms as major data warehousing and advertising platforms, as well as the platforms' role in "surveillance capitalism" (Zuboff, 2015). To understand this growing duality, it is useful to recognize different levels of data access in terms of who is accessing social media data and for what purposes. Common scenarios of social media data collection and use include: (1) social media platforms 
collecting data for targeted marketing; (2) social media platforms analyzing data for internal purposes (e.g., to improve the user experience on the platform); (3) social media platforms sharing data with affiliates and partners; (4) users sharing data with third-party developers; and (5) third parties accessing data using the platforms' API without users' consent. While there are many ways to collect and use social media data, our research demonstrates that social media users still have concerns with unauthorized access to, and secondary use of, their personal data.

From a marketing perspective, a major challenge is how to mitigate privacy concerns while increasing the perceived benefits of using social media data for marketing. The study supports the idea that creating clear privacy policies is necessary (Arnold, 2018; Goldfarb \& Tucker, 2013), but not sufficient. Prior research shows that most users skim or do not read privacy policies and terms of use because the platforms discourage engagement using confusing and time-consuming legalese (Obar \& Oeldorf-Hirsch, 2018). In order to achieve the potential benefits of data sharing, social media platforms and brands should adhere to transparent consumer-oriented privacy policy practices (e.g., OPC, 2018); they also need to empower users with a higher-level of control over what information they want to share, with whom, and for what purpose (Prince, 2018). Consumers trust in social media platforms and comfort with digital marketing practices may increase if platforms limit the access to individuals' personal data, improve transparency about the collection and use of personal data, implement opt-in procedures, and offer monetary or non-monetary benefits to consumers (Jai \& King, 2016). Furthermore, social media platforms may leverage increased privacy controls and opt-in procedures to improve the performance and effectiveness of targeted advertising (Tucker, 2014).

The study shows that targeted advertising is the strongest contributing element to marketing comfort. It is likely that consumers are more familiar with, and have more direct exposure to, targeted ads than the other two dimensions: opinion mining and customer relations. The use of social media data for opinion mining and customer relations are more masked, which means the implications of these practices are less apparent to average social media users. This finding points to the need for consumer education on the emerging marketing practices that may be less apparent in the day-to-day use of social media. Digital literacy will continue to be crucial as technologies evolve and new ways to use individuals' data emerge. The onus does not only lie with individuals; rather, third parties that use the data need to be held to higher ethical standards.

Ethical issues have always arisen in marketing, but marketing professionals are now tasked with more complex and insidious ethical situations that require a high level of technical and ethical literacy. The impact of a particular decision or action made by a marketing professional may not be immediately obvious, or ever become apparent to the public, but there may still be critical implications for consumers. Recent high-profile news stories evidence the perils of social media marketing, such as the ability to target advertising to racists and bigots on Facebook (e.g., using Facebook's functionality to target "Jew-haters" as a demographic variable or use the filtering mechanism to not display ads to people with "ethnic affinities") (Maheshwari \& Isaac, 2017). Sparks and Hunt (1998) find that marketers' ethical sensitivity is achieved through socialization and an understanding of the ethical norms. For social media marketing to be executed effectively 
and ethically, the recipient of the marketing material - the consumer-needs to be comfortable with the practices.

As the practices of using social media in marketing are still developing, we advocate for ethics and consideration of consumers' concerns to be integrated into marketers' practices moving forward. Decision-makers should consider the norms of all relevant communities and thus ensure "a broad consideration of stakeholder interests" (Dunfee, Smith, \& Ross, 1999, p. 28). The decision-makers - in this case, marketers - need to recognize and consider all the stakeholders that may be impacted by the decision or action, especially because customers' trust and confidence is a required factor for marketers to maintain a positive long-term relationship with them. Therefore, it is not only an ethical practice, but a practice that also makes sound business sense.

\section{Conclusion}

There is a lack of understanding related to consumers' perceptions about marketers' use of their public social media data due to its recent emergence, the complexity of the issues, and the dearth of research in this area. Using communication privacy management theory as a theoretical lens, the research analyzes the public's perceptions of this practice to better inform ethical marketing practices using a census-balanced sample of the online adult Canadian population. There are two major scholarly contributions of this research: (1) the extension and applicability of communication privacy management theory to social media, and (2) the introduction of marketing comfort, a new construct of high importance for future marketing research. The 7-point Likert scale measures individuals' comfort with marketers' use of social media data by aggregating three common functions of using social media data for marketing: extracting insights via opinion mining, delivering information via targeted advertising, and communicating via customer relations with new or existing customers. We hope that the construct will be further tested, and we encourage other researchers to apply this construct when using both public and private data (as this research focuses on publicly available data), and in other countries to confirm the results of this study.

From a practical perspective, while it is usually legally permissible for third parties, such as marketers, to mine and use publicly available social media data, our research evidences that many people are not comfortable with this practice; as such, users' attitudes may influence their purchasing behaviour, which would critically impact marketers' practices. Considering that the vast majority of online users are uncomfortable with marketers using their publicly available social media data, this research has implications for the wider marketing community and marketing ethics. There is an opportunity for marketers to inform and reassure the public about the ethical integrity of how they are using the data (e.g., in aggregate rather than individually), but this requires the development and communication of these ethical standards by all marketing practitioners. The marketing community can, and must, develop professional principles and guidelines on social media data use that still affords them the ability to benefit from social media data, but better speak to the concerns of consumers. 


\subsection{Limitations and future research directions}

There may be cultural specificities that are important to consider in understanding comfort with marketers use of social media (Tsai \& Men, 2012); thus, further research should seek to analyze this topic cross-culturally. We also encourage future research to incorporate other factors of the theory (e.g., culture, gender, motivation, trust, or context) to improve the predictive power of this model.

As discussed in the methods section, a limitation of the research model is its focus on social media in general, without consideration of the platform being used. We acknowledge that different platforms may provide different uses and gratifications, and they also may trigger different privacy concerns - e.g., concerns about the use of personal and activity data by Facebook after the Cambridge Analytica scandal - , but it is also worth noting that this research does not consider any specific brand or company. This is a relevant issue because users might expect that all the data they share with a social media platform is also collected, analyzed, and used by the different brands they follow and interact with, or at least every interaction with the company. Such a consideration is out of the scope of the present study; however, if this is the case, the level of perceived trustworthiness - e.g., the ability, benevolence, and integrity (Mayer, Davis, \& Schoorman, 1995) — of the company might help increase the predictive power of the model. This process may be reinforced if trust transfer happens, be it between targets (i.e. the social media platform and the company) or from a context (i.e. from the company's offline/online marketing practices to the social media context) (Stewart, 2003). Future research can analyze whether the explanatory power may be increased if social media platforms are analyzed in isolation. Aligned with Kamboj, Sarmah, Gupta, and Dwivedi (2018), all social media platforms were considered in this research, but future research could examine how these factors may manifest differently in different platforms, as recommended by Alalwan (2018) and Alalwan, Rana, Dwivedi, and Algharabat (2017).

The analysis also yields low predictive relevance of the model, with a total variance explained of $18 \%$ of marketing comfort. This result does not limit the validity of the relationships found in the analysis and is partially explained by the high number of respondents that are extremely uncomfortable with the use of their personal and activity data for marketing purposesespecially for targeted advertisement. Because a group-based segmentation approach is beyond the scope of this research, further research should investigate whether segmentation of consumers based on their privacy concerns and their uses and gratifications of social media could better explain marketing comfort - e.g., pragmatists, fundamentalists, and unconcerned (DMA, 2018a). The results point to the need for further refinement of the concept - especially, for investigation of antecedents of marketing comfort that may improve the accuracy of predictions, such as the above-mentioned perceived trustworthiness or the consumers' level of perceived control over how their data are used (Goldfarb \& Tucker, 2013).

Future work should also ask questions related to uses and gratifications in the context of advertising (O'Donohoe, 1994). Furthermore, future work should address consumer intention and behaviour as a response to concerns of marketers using consumers' social media data. Considering 
the recent changes to Facebook's ad platform that explicitly identifies why users are seeing a particular ad, future research should analyze how these disclaimers influence people's comfort with the practice of microtargeting. As of 2018, Facebook only applies this form of disclosure to political ads, but we contend this practice should be expanded to other forms of advertising and other social media platforms. Since the Cambridge Analytica scandal and the new General Data Protection Regulation in the European Union, there continues to be a growing need to understand consumers' attitudes towards the use of their social media data.

\section{Acknowledgements}

This research is supported in part through a five-year initiative on "Social Media Data Stewardship" funded by the Canada Research Chairs program (2015-2020; Principal Investigator: Gruzd, A.), eCampusOntario research funding and the Ted Rogers School of Management at Ryerson University. The authors would like to thank Elizabeth Dubois for her collaboration in the development of the survey design; Jordan Kilfoy, Christine Gagnon, and Jocelyn Stéphane Cadieux for their help with the French translation of the survey; and members of the Social Media Lab at Ryerson University for their feedback on the survey design.

\section{References}

Acquisti, A., \& Gross, R. (2006). Imagined Communities: Awareness, Information Sharing, and Privacy on the Facebook. In G. Danezis \& P. Golle (Eds.), Privacy Enhancing Technologies (pp. 36-58). Springer Berlin Heidelberg. https://doi.org/10.1007/11957454_3

Adjei, M. T., Noble, S. M., \& Noble, C. H. (2010). The influence of C2C communications in online brand communities on customer purchase behavior. Journal of the Academy of Marketing Science, 38(5), 634-653. https://doi.org/10.1007/s11747-009-0178-5

Akar, E., \& Topçu, B. (2011). An Examination of the Factors Influencing Consumers' Attitudes Toward Social Media Marketing. Journal of Internet Commerce, 10(1), 35-67. https://doi.org/10.1080/15332861.2011.558456

Alalwan, A. A. (2018). Investigating the impact of social media advertising features on customer purchase intention. International Journal of Information Management, 42, 65-77. http://doi.org/10.1016/j.ijinfomgt.2018.06.001

Alalwan, A. A., Rana, N. P., Dwivedi, Y. K., \& Algharabat, R. (2017). Social media in marketing: A review and analysis of the existing literature. Telematics and Informatics, 34(7), 1177-1190. https://doi.org/10.1016/j.tele.2017.05.008

Alashoor, T., Han, S., \& Joseph, R. (2017). Familiarity with Big Data, Privacy Concerns, and Self-disclosure Accuracy in Social Networking Websites: An APCO Model. Communications of the Association for Information Systems, 41(1). Retrieved from http://aisel.aisnet.org/cais/vol41/iss1/4

Amato-McCoy, D. M. (2018, March 6). Marimekko taps social media data to create customerdriven assortments. Chain Store Age. Retrieved from https://www.chainstoreage.com/technology/marimekko-taps-social-media-data-createcustomer-driven-assortments/

Ainin, S., Parveen, F., Moghavvemi, S., Jaafar, N. I., \& Mohd Shuib, N. L. (2015). Factors influencing the use of social media by SMEs and its performance outcomes. Industrial 
Management \& Data Systems, 115(3), 570-588. https://doi.org/10.1108/IMDS-07-20140205

Arnold, A. (2018). Consumer trust in social media is declining: Here's how brands should change their strategies. Forbes. Retrieved from https://www.forbes.com/sites/andrewarnold/2018/07/29/consumer-trust-in-social-mediais-declining-heres-how-brands-should-change-their-strategies

Bailey, A. A., Bonifield, C. M., \& Arias, A. (2018). Social media use by young Latin American consumers: An exploration. Journal of Retailing and Consumer Services, 43, 10-19. https://doi.org/10.1016/j.jretconser.2018.02.003

Barger, V., Peltier, J. W., \& Schultz, D. E. (2016). Social media and consumer engagement: a review and research agenda. Journal of Research in Interactive Marketing, 10(4), 268287. https://doi.org/10.1108/JRIM-06-2016-0065

Baruh, L., Secinti, E., \& Cemalcilar, Z. (2017). Online Privacy Concerns and Privacy Management: A Meta-Analytical Review. Journal of Communication, 67(1), 26-53.

Bellman, S., Lecturer, S., Johnson, E. J., Kobrin, S. J., Wurster, W. H., Management, P. M., \& Lohse, G. L. (2004). International Differences in Information Privacy Concerns: A Global Survey of Consumers. The Information Society, 313-324.

Blatterer, H. (2010). Social Networking, Privacy, and the Pursuit of Visibility. In H. Blatterer, P. Johnson, \& M. R. Markus (Eds.), Modern Privacy: Shifting Boundaries, New Forms (pp. 73-87). London: Palgrave Macmillan UK. https://doi.org/10.1057/9780230290679_6

Boateng, H., \& Okoe, A. F. (2015). Consumers' attitude towards social media advertising and their behavioural response: The moderating role of corporate reputation. Journal of Research in Interactive Marketing, 9(4), 299-312. https://doi.org/10.1108/JRIM-012015-0012

Boerman, S. C., Kruikemeier, S., \& Borgesius, F. J. Z. (2017). Online Behavioral Advertising: A Literature Review and Research Agenda. Journal of Advertising, 46(3), 363-376. https://doi.org/10.1080/00913367.2017.1339368

Cavusoglu, H., Phan, T. Q., Cavusoglu, H., \& Airoldi, E. M. (2016). Assessing the Impact of Granular Privacy Controls on Content Sharing and Disclosure on Facebook. Information Systems Research, 27(4), 848-879. https://doi.org/10.1287/isre.2016.0672

Chang, C. C., Hung, S.-W., Cheng, M.-J., \& Wu, C.-Y. (2015). Exploring the intention to continue using social networking sites: The case of Facebook. Technological Forecasting and Social Change, 95, 48-56.

Cheung, C., Lee, Z. W. Y., \& Chan, T. K. H. (2015). Self-disclosure in social networking sites: The role of perceived cost, perceived benefits and social influence. Internet Research, 25(2), 279-299. https://doi.org/10.1108/IntR-09-2013-0192

Child, J. T., Haridakis, P. M., \& Petronio, S. (2012). Blogging privacy rule orientations, privacy management, and content deletion practices: The variability of online privacy management activity at different stages of social media use. Computers in Human Behavior, 28(5), 1859-1872. https://doi.org/10.1016/j.chb.2012.05.004Citton, Y. (2017). The Ecology of Attention. Cambridge, UK: Wiley.

Cochrane, K. (2018). To Regain Consumers' Trust, Marketers Need Transparent Data Practices. Harvard Business Review. Available online: https://hbr.org/2018/06/to-regainconsumers-trust-marketers-need-transparent-data-practices

Conroy, P., Milano, F., Narula A., \& Singhal, R. (2014). Building consumer trust: Protecting personal data in the consumer product industry. Deloitte University Press, 1-28. 
Culnan M. J., \& Armstrong, P. K. (1999). Information privacy concerns, procedural fairness, and impersonal trust: an empirical investigation. Organization Science, 10, 104-115.

Dance, G. J. X., LaForgia, M., \& Confessore, N. (2018, December 18). As Facebook Raised a Privacy Wall, It Carved an Opening for Tech Giants. The New York Times. Retrieved December 19, 2018, from https://www.nytimes.com/2018/12/18/technology/facebookprivacy.html

Das, S., \& Kramer, A. D. (2013). Self-Censorship on Facebook. In Proceedings of the Seventh International AAAI Conference on Weblogs and Social Media (pp. 120-127).

Debatin, B., Lovejoy, J. P., Horn, A.-K., \& Hughes, B. N. (2009). Facebook and Online Privacy: Attitudes, Behaviors, and Unintended Consequences. Journal of Computer-Mediated Communication, 15(1), 83-108. https://doi.org/10.1111/j.1083-6101.2009.01494.x

DeGroot, J. M., \& Vik, T. A. (2017). "We were not prepared to tell people yet": Confidentiality breaches and boundary turbulence on Facebook. Computers in Human Behavior, 70, 351-359.

Dimitriu, R., \& Guesalaga, R. (2017). Consumers' Social Media Brand Behaviors: Uncovering Underlying Motivators and Deriving Meaningful Consumer Segments. Psychology \& Marketing, 34(5), 580-592. https://doi.org/10.1002/mar.21007

DMA (2018a). Data privacy: What the consumer really thinks. The Direct Marketing Association. Retrieved from https://dma.org.uk/uploads/misc/5a857c4fdf846-dataprivacy---what-the-consumer-really-thinks-final_5a857c4fdf799.pdf

DMA (2018b). GDPR: A consumer perspective. The Direct Marketing Association. Retrieved from https://dma.org.uk/uploads/misc/5af5497c03984-gdpr-consumer-perspective-2018v1_5af5497c038ea.pdf

Dubois, E., Gruzd, A., Jacobson, J., 2018. Journalists' use of social media to infer public opinion: the citizens' perspective. Soc. Sci. Comput. Rev. 1-18. https://doi.org/10.1177/0894439318791527

Dunfee, T. W., Smith, N. C., \& Ross, W. T. (1999). Social Contracts and Marketing Ethics. Journal of Marketing, 63(3), 14. https://doi.org/10.2307/1251773

Dwivedi, Y. K., Kapoor, K. K., \& Chen, H. (2015). Social media marketing and advertising. The Marketing Review, 15(3), 289-309. https://doi.org/10.1362/146934715X14441363377999

Eppler, M. J., \& Mengis, J. (2004). The Concept of Information Overload: A Review of Literature from Organization Science, Accounting, Marketing, MIS, and Related Disciplines. The Information Society, 20(5), 325-344. https://doi.org/10.1080/01972240490507974

Felix, R., Rauschnabel, P. A., \& Hinsch, C. (2017). Elements of strategic social media marketing: A holistic framework. Journal of Business Research, 70, 118-126. https://doi.org/10.1016/j.jbusres.2016.05.001

Finucane, M. L., Slovic, P., Mertz, C. K., Flynn, J., \& Satterfield, T. A. (2000). Gender, race, and perceived risk: The "white male" effect. Health, Risk \& Society, 2(2), 159-172. https://doi.org/10.1080/713670162

Fox, J., \& Moreland, J. J. (2015). The dark side of social networking sites: An exploration of the relational and psychological stressors associated with Facebook use and affordances. Computers in Human Behavior, 45, 168-176. https://doi.org/10.1016/j.chb.2014.11.083 
Freelon, D., Watanabe, M., Busch, L., \& Kawabata, A. (2008). Town halls of the digital age: Controversy and ideology in online deliberation (and beyond). In Conference of the Association of Internet Researchers, Copenhagen, Denmark.

Giles, E. L., Becker, F., Ternent, L., Sniehotta, F. F., McColl, E., \& Adams, J. (2016). Acceptability of Financial Incentives for Health Behaviours: A Discrete Choice Experiment. PLOS ONE, 11(6), e0157403. https://doi.org/10.1371/journal.pone.0157403

Goldfarb, A., \& Tucker, C. (2013). Why managing consumer privacy can be an opportunity. MIT Sloan Management Review, 54(3), 10-12.

Gruzd, A., Hernández-García, Á., 2018. Privacy concerns and self-disclosure in private and public uses of social media. Cyberpsychol. Behav. Soc. Netw. 21 (7), 418-428. https://doi.org/10.1089/cyber.2017.0709

Gruzd, A., Jacobson, J., Mai, P., Dubois, E., 2018a. The state of social media in Canada. Ryerson Social Media Lab. https://doi.org/10.5683/SP/AL8Z6R

Gruzd, A., Jacobson, J., Mai, P., Dubois, E., 2018b. Social media privacy in Canada. Ryerson Social Media Lab. https://doi.org/10.2139/ssrn.3195503

Gruzd, A., Paulin, D., \& Haythornthwaite, C. (2016). Analyzing Social Media And Learning Through Content And Social Network Analysis: A Faceted Methodological Approach. Journal of Learning Analytics, 3(3), 46-71.

Gundecha, P., \& Liu, H. (2012). Mining Social Media: A Brief Introduction. In 2012 TutORials in Operations Research (pp. 1-17). INFORMS. https://doi.org/10.1287/educ.1120.0105

Jai, T-M., \& King, N. J. (2016). Privacy versus reward: Do loyalty programs increase consumers' willingness to share personal information with third-party advertisers and data brokers? Journal of Retailing and Consumer Services, 28, 296-303

Hair, J. F., Hult, G. T. M., Ringle, C. M., \& Sarstedt, M. (2017). A primer on partial least squares structural equation modeling (PLS-SEM) (Second edition). Los Angeles: Sage.

Hair, J. F., Sarstedt, M., Ringle, C. M., \& Gudergan, S. P. (2018). Advanced issues in partial least squares structural equation modeling. Los Angeles: SAGE.

Hair, J., Hollingsworth, C. L., Randolph, A. B., \& Loong Chong, A. Y. (2017). An updated and expanded assessment of PLS-SEM in information systems research. Industrial Management \& Data Systems, 117(3), 442-458. https://doi.org/10.1108/IMDS-04-2016$\underline{0130}$

Hayes, A. F., Glynn, C. J., \& Shanahan, J. (2005). Willingness to Self-Censor: A Construct and Measurement Tool for Public Opinion Research. International Journal of Public Opinion Research, 17(3), 298-323. https://doi.org/10.1093/ijpor/edh073

Hazari, S., \& Brown, C. (2013). An Empirical Investigation of Privacy Awareness and Concerns on Social Networking Sites. Journal of Information Privacy and Security, 9(4), 31-51. https://doi.org/10.1080/15536548.2013.10845689

He, W., Zha, S., \& Li, L. (2013). Social media competitive analysis and text mining: A case study in the pizza industry. International Journal of Information Management, 33(3), 464-472. https://doi.org/10.1016/j.ijinfomgt.2013.01.001

Henseler, J., Ringle, C. M., \& Sarstedt, M. (2015). A new criterion for assessing discriminant validity in variance-based structural equation modeling. Journal of the Academy of Marketing Science, 43(1), 115-135. https://doi.org/10.1007/s11747-014-0403-8

Hunt, S. D., \& Vitell, S. (1986). A General Theory of Marketing Ethics. Journal of Macromarketing, 6(1), 5-16. https://doi.org/10.1177/027614678600600103 
Hunt, S. D., \& Vitell, S. J. (2006). The General Theory of Marketing Ethics: A Revision and Three Questions. Journal of Macromarketing, 26(2), 143-153. https://doi.org/10.1177/0276146706290923

Ismagilova, E., Slade, E., Rana, N. P., \& Dwivedi, Y. K. (2019). The effect of characteristics of source credibility on consumer behaviour: A meta-analysis. Journal of Retailing and Consumer Services. DoI: https://doi.org/10.1016/j.jretconser.2019.01.005

Jeong, Y., \& Kim, Y. (2017). Privacy concerns on social networking sites: Interplay among posting types, content, and audiences. Computers in Human Behavior, 69, 302-310. https://doi.org/10.1016/j.chb.2016.12.042

Jiang, Z., Chan, J., Tan, B., \& Chua, W. S. (2010). Effects of Interactivity on Website Involvement and Purchase Intention. Journal of the Association for Information Systems, 11(1). Retrieved from https://aisel.aisnet.org/jais/vol11/iss1/1

Jung, A.-R. (2017). The Influence of Perceived Ad Relevance on Social Media Advertising. Computers in Human Behaviour, 70, 303-309. https://doi.org/10.1016/j.chb.2017.01.008

Kang, J.-Y. M., \& Kim, J. (2017). Online customer relationship marketing tactics through social media and perceived customer retention orientation of the green retailer. Journal of Fashion Marketing and Management: An International Journal, 21(3), 298-316. https://doi.org/10.1108/JFMM-08-2016-0071

Kanter, J. (2018). Trust in Facebook has spectacularly nosedived after its enormous data breach. Business Insider. Retrieved on December 19, 2018, from https://www.businessinsider.com/facebook-trust-collapses-after-cambridge-analyticadata-scandal-2018-4

Kamboj, S., Sarmah, B., Gupta, S., \& Dwivedi, Y. (2018). Examining branding co-creation in brand communities on social media: Applying the paradigm of Stimulus-OrganismResponse. International Journal of Information Management, 39, 169-185. https://doi.org/10.1016/j.ijinfomgt.2017.12.001

Kapoor, K. K., Tamilmani, K., Rana, N. P., Patil, P., Dwivedi, Y. K., \& Nerur, S. (2018). Advances in Social Media Research: Past, Present and Future. Information Systems Frontiers, 20(3), 531-558. https://doi.org/10.1007/s10796-017-9810-y

Kietzmann, J. H. (2011). Social media? Get serious! Understanding the functional building blocks of social media. Business Horizons, 54(3), 241-251.

Laczniak, G. R., \& Murphy, P. E. (2006). Normative Perspectives for Ethical and Socially Responsible Marketing. Journal of Macromarketing, 26(2), 154-177. https://doi.org/10.1177/0276146706290924

Lai, C.-Y., \& Yang, H.-L. (2015). Determinants of individuals' self-disclosure and instant information sharing behavior in micro-blogging. New Media \& Society, 17(9), 14541472. https://doi.org/10.1177/1461444814528294

Lee, I. (2018). Social media analytics for enterprises: Typology, methods, and processes. Business Horizons, 61(2), 199-210.

Lee, J., \& Hong, I. B. (2016). Predicting positive user responses to social media advertising: The roles of emotional appeal, informativeness, and creativity. International Journal of Information Management, 36(3), 360-373.

Leung, L. (2002). Loneliness, Self-Disclosure, and ICQ (“I Seek You”) Use. CyberPsychology \& Behavior, 5(3), 241-251. https://doi.org/10.1089/109493102760147240 
Liu, X., Burns, A. C., \& Hou, Y. (2017). An Investigation of Brand-Related User-Generated Content on Twitter. Journal of Advertising, 46(2), 236-247. https://doi.org/10.1080/00913367.2017.1297273

Maheshwari, S., \& Isaac, M. (2017, September 20). Facebook, After 'Fail' Over Ads Targeting Racists, Makes Changes. The New York Times. Retrieved from https://www.nytimes.com/2017/09/20/business/media/facebook-racist-ads.html

Malhotra, N. K., Kim, S. S., \& Agarwal, J. (2004). Internet Users' Information Privacy Concerns (IUIPC): The Construct, the Scale, and a Causal Model. Information Systems Research, 15(4), 336-355.

Malhotra, N. K., \& Miller, G. L. (1998). An integrated model for ethical decisions in marketing research. Journal of Business Ethics, 17(3), 263-280.

Malthouse, E. C., \& Li, H. (2017). Opportunities for and Pitfalls of Using Big Data in Advertising Research. Journal of Advertising, 46(2), 227-235. https://doi.org/10.1080/00913367.2017.1299653

Martín-Consuegra, D., Díaz, E., Gómez, M., \& Molina, A. (2018). Examining consumer luxury brand-related behavior intentions in a social media context: The moderating role of hedonic and utilitarian motivations. Physiology \& Behavior. https://doi.org/10.1016/j.physbeh.2018.03.028

Marwick, A., \& Hargittai, E. (2018). Nothing to hide, nothing to lose? Incentives and disincentives to sharing information with institutions online. Information, Communication \& Society, 1-17. https://doi.org/10.1080/1369118X.2018.1450432

Mayer, R. C., Davis, J. H., \& Schoorman, F. D. (1995). An integrative model of organizational trust. Academy of Management Review, 20(3), 709-734.

Misirlis, N., \& Vlachopoulou, M. (2018). Social media metrics and analytics in marketing S3M: A mapping literature review. International Journal of Information Management, 38(1), 270-276. https://doi.org/10.1016/j.ijinfomgt.2017.10.005

Murphy, P. E., Laczniak, G. R., \& Wood, G. (2007). An ethical basis for relationship marketing: a virtue ethics perspective. European Journal of Marketing, 41(1/2), 37-57. https://doi.org/10.1108/03090560710718102

Obar, J. A., \& Oeldorf-Hirsch, A. (2018). The biggest lie on the Internet: ignoring the privacy policies and terms of service policies of social networking services. Information, Communication \& Society, 1-20. https://doi.org/10.1080/1369118X.2018.1486870

O'Donohoe, S. (1994). Advertising Uses and Gratifications. European Journal of Marketing, 28(8/9), 52-75. https://doi.org/10.1108/03090569410145706

OPC (2018). Ten tips for a better online privacy policy and improved privacy practice transparency. Available at: https://www.priv.gc.ca/en/privacy-topics/privacypolicies/02_05_d_56_tips2/

Osatuyi, B. (2015). Empirical Examination of Information Privacy Concerns Instrument in the Social Media Context. AIS Transactions on Replication Research, 1(1). Retrieved from http://aisel.aisnet.org/trr/vol1/iss1/3

Paniagua, J., \& Sapena, J. (2014). Business performance and social media: Love or hate? Business Horizons, 57(6), 719-728.

Peppers, D., \& Rogers, M. (2017). Managing Customer Relationships: A Strategic Framework. Hoboken, NJ: Wiley.

Petronio, S. (2002). Boundaries of Privacy: Dialectics of Disclosure. SUNY Press. 
Prince, C. (2018). Do consumers want to control their personal data? Empirical evidence. International Journal of Human-Computer Studies, 110, 21-32.

Proudfoot, J. G., Wilson, D., Valacich, J. S., \& Byrd, M. D. (2018). Saving face on Facebook: privacy concerns, social benefits, and impression management. Behaviour \& Information Technology, 37(1), 16-37. https://doi.org/10.1080/0144929X.2017.1389988

Quan-Haase, A., \& Young, A. L. (2010). Uses and Gratifications of Social Media: A Comparison of Facebook and Instant Messaging. Bulletin of Science, Technology \& Society, 30(5), 350-361. https://doi.org/10.1177/0270467610380009

Quinn, K. (2016). Why We Share: A Uses and Gratifications Approach to Privacy Regulation in Social Media Use. Journal of Broadcasting \& Electronic Media, 60(1), 61-86. https://doi.org/10.1080/08838151.2015.1127245

Ruddick, G. (2016, November 2). Facebook forces Admiral to pull plan to price car insurance based on posts. The Guardian. Retrieved on December 19, 2018 from https://www.theguardian.com/money/2016/nov/02/facebook-admiral-car-insuranceprivacy-data

Royle, J., \& Laing, A. (2014). The digital marketing skills gap: Developing a Digital Marketer Model for the communication industries. International Journal of Information Management, 34(2), 65-73.

Schweidel, D. A., \& Moe, W. W. (2014). Listening In on Social Media: A Joint Model of Sentiment and Venue Format Choice. Journal of Marketing Research, 51(4), 387-402. https://doi.org/10.1509/jmr.12.0424

Shareef, M. A., Mukerji, B., Alryalat, M. A. A., Wright, A., \& Dwivedi, Y. K. (2018). Advertisements on Facebook: Identifying the persuasive elements in the development of positive attitudes in consumers. Journal of Retailing and Consumer Services, 43, 258268. https://doi.org/10.1016/j.jretconser.2018.04.006

Shareef, M. A., Mukerji, B., Dwivedi, Y. K., Rana, N. P., \& Islam, R. (2019). Social media marketing: Comparative effect of advertisement sources. Journal of Retailing and Consumer Services, 46, 58-69.

Sheng, J., Amankwah-Amoah, J., \& Wang, X. (2018). Technology in the 21st century: New challenges and opportunities. Technological Forecasting and Social Change. https://doi.org/10.1016/j.techfore.2018.06.009

Simmons, G. (2008). Marketing to postmodern consumers: introducing the internet chameleon. European Journal of Marketing, 42(3/4), 299-310. https://doi.org/10.1108/03090560810852940

Singhapakdi, A., Vitell, S. J., \& Kraft, K. L. (1996). Moral Intensity and Ethical DecisionMaking of Marketing Professionals. Journal of Business Research, 36, 245-255.

Smith, H., Milberg, S., \& Burke, S. (1996). Information Privacy: Measuring Individuals' Concerns about Organizational Practices. Management Information Systems Quarterly, 20(2). Retrieved from https://aisel.aisnet.org/misq/vol20/iss2/3

Son, J.-Y., \& Kim, S. S. (2008). Internet Users' Information Privacy-Protective Responses: A Taxonomy and a Nomological Model. MIS Quarterly, 32(3), 503-529.

Soler-Labajos, N., \& Jimenez-Zarco, A. I. (2016). Social CRM: The Role of Social Media in Managing Customer Relations. In A. Singh \& P. Duhan (Eds.), Managing Public Relations and Brand Image through Social Media. Hershey, PA: IGI Global. 
Sparks, J. R., \& Hunt, S. D. (1998). Marketing Researcher Ethical Sensitivity: Conceptualization, Measurement, and Exploratory Investigation. Journal of Marketing, 62(2), 92-109. https://doi.org/10.2307/1252163

Sterne, J. (2010). Social Media Metrics: How to Measure and Optimize Your Marketing Investment. John Wiley \& Sons.

Stewart, K. J. (2003). Trust transfer on the world wide web. Organization Science, 14(1), 5-17.

Stewart, K. A., \& Segars, A. H. (2002). An Empirical Examination of the Concern for Information Privacy Instrument. Information Systems Research, 13(1), 36-49. https://doi.org/10.1287/isre.13.1.36.97

Sundar, S. S., \& Limperos, A. M. (2013). Uses and Grats 2.0: New Gratifications for New Media. Journal of Broadcasting \& Electronic Media, 57(4), 504-525. https://doi.org/10.1080/08838151.2013.845827

Tsai, W., \& Men, L. R. (2012). Cultural values reflected in corporate pages on popular social network sites in China and the United States. Journal of Research in Interactive Marketing, 6(1), 42-58. https://doi.org/10.1108/17505931211241369

Tucker, C. E. (2014). Social Networks, Personalized Advertising, and Privacy Controls. Journal of Marketing Research, 51(5), 546-562.

Tuten, T. L., \& Solomon, M. R. (2017). Social Media Marketing. SAGE.

van Dijck, J. (2009). Users like you? Theorizing agency in user-generated content. Media, Culture, and Society, 31(1), 41-58.

van Dijck, J. (2012). Facebook as a tool for producing sociality and connectivity. Television \& New Media, 13(2), 160-176.

Vinodhini, G., \& Chandrasekaran, R. M. (2012). Sentiment analysis and opinion mining: a survey. International Journal, 2(6), 282-292.

Vitell, S. J. (2003). Consumer Ethics Research: Review, Synthesis and Suggestions for the Future. Journal of Business Ethics, 43, 33-47.

Wang, Y., \& Fesenmaier, D. R. (2004). Modeling Participation in an Online Travel Community. Journal of Travel Research, 42(3), 261-270. https://doi.org/10.1177/0047287503258824

Ward, K. (2018). Social networks, the 2016 US presidential election, and Kantian ethics: applying the categorical imperative to Cambridge Analytica's behavioral microtargeting. Journal of Media Ethics, 33(3), 133-148. https://doi.org/10.1080/23736992.2018.1477047

Waters, S., \& Ackerman, J. (2011). Exploring privacy management on Facebook: Motivations and perceived consequences of voluntary disclosure. Journal of Computer-Mediated Communication, 17(1), 101-115.

Western Digital. (2018, March 6). Mining your social media data to make travel more personalised | Forbes India Blog. Forbes India. Retrieved from http://www.forbesindia.com/blog/uncategorized/mining-your-social-media-data-to-maketravel-more-personalised/

Wheeless, L. R. (1976). Self-Disclosure and Interpersonal Solidarity: Measurement, Validation, and Relationships. Human Communication Research, 3(1), 47-61. https://doi.org/10.1111/j.1468-2958.1976.tb00503.x

Wheeless, L. R. (1978). A Follow-up Study of the Relationships Among Trust, Disclosure, and Interpersonal Solidarity. Human Communication Research, 4(2), 143-157. https://doi.org/10.1111/j.1468-2958.1978.tb00604.x 
Yang, W.-S., Dia, J.-B., Cheng, H.-C., \& Lin, H.-T. (2006). Mining social networks for targeted advertising. In System Sciences, 2006. HICSS'06. Proceedings of the 39th Annual Hawaii International Conference on System Sciences (Vol. 6, pp. 137a-137a). IEEE.

Zmud, J., Sener, I. N., \& Wagner, J. (2016). Self-Driving Vehicles: Determinants of Adoption and Conditions of Usage. Transportation Research Record: Journal of the Transportation Research Board, 2565, 57-64. https://doi.org/10.3141/2565-07

Zuboff, S. (2015). Big other: surveillance capitalism and the prospects of an information civilization. Journal of Information Technology, 30(1), 75-89. 


\section{Appendices}

\section{Appendix 1: Measurement instrument}

\begin{tabular}{|c|c|c|c|c|}
\hline \multicolumn{3}{|c|}{ Self-Disclosure (Wheeless, 1976; Lai \& Yang, 2015) } & Mean & SD \\
\hline \multicolumn{5}{|c|}{$\begin{array}{l}\text { When using your public account(s), to what extent do you agree with the following statements? }(1= \\
\text { Strongly agree, } 7 \text { = Strongly disagree })\end{array}$} \\
\hline \multirow{6}{*}{$\begin{array}{l}\text { Amount and } \\
\text { Depth (SDAD) }\end{array}$} & SDAD1 & I usually talk about myself on social media for fairly long periods & 5,84 & 1,47 \\
\hline & SDAD2 & I often discuss my feelings about myself on social media & 5,35 & 1,64 \\
\hline & SDAD3 & I often express my personal beliefs and opinions on social media & 4,52 & 1,86 \\
\hline & SDAD4 & $\begin{array}{l}\text { I typically reveal information about myself on social media without } \\
\text { intending to }\end{array}$ & 5,34 & 1,61 \\
\hline & SDAD5 & $\begin{array}{l}\text { I often disclose intimate, personal things about myself on social media } \\
\text { without hesitation }\end{array}$ & 5,81 & 1,48 \\
\hline & SDAD6 & When I post about myself on social media, the posts are fairly detailed & 5,04 & 1,58 \\
\hline \multirow{3}{*}{ Polarity (SDPN) } & SDPN1 & I usually disclose positive things about myself on social media & 3,29 & 1,56 \\
\hline & SDPN2 & I normally express my good feelings about myself on social media & 3,62 & 1,69 \\
\hline & SDPN3 & $\begin{array}{l}\text { On the whole, my disclosures about myself on social media are more } \\
\text { positive than negative }\end{array}$ & 2,75 & 1,37 \\
\hline \multirow{4}{*}{ Accuracy (SDAc) } & SDAc1 & $\begin{array}{l}\text { My expressions of my own feelings, emotions, and experiences on } \\
\text { social media are true reflections of myself }\end{array}$ & 2,96 & 1,54 \\
\hline & SDAc2 & $\begin{array}{l}\text { My self-disclosures on social media are completely accurate } \\
\text { reflections of who I really am }\end{array}$ & 3,12 & 1,51 \\
\hline & SDAc3 & $\begin{array}{l}\text { My self-disclosures on social media can accurately reflect my own } \\
\text { feelings, emotions, and experiences }\end{array}$ & 3,31 & 1,58 \\
\hline & SDAc4 & $\begin{array}{l}\text { My statements about my own feelings, emotions, and experiences on } \\
\text { social media are always accurate self-perceptions }\end{array}$ & 3,08 & 1,48 \\
\hline \multirow{3}{*}{ Intent (SDI) } & SDI1 & $\begin{array}{l}\text { When I express my personal feelings on social media, I am always } \\
\text { aware of what I am doing and saying }\end{array}$ & 2,33 & 1,37 \\
\hline & SD2 & $\begin{array}{l}\text { When I reveal my feelings about myself on social media, I } \\
\text { consciously intend to do so }\end{array}$ & 2,88 & 1,63 \\
\hline & SDI3 & $\begin{array}{l}\text { When I self-disclose on social media, I am consciously aware of what } \\
\text { I am revealing }\end{array}$ & 2,32 & 1,34 \\
\hline \multicolumn{5}{|c|}{ Uses \& Gratification (Cheung, Lee, \& Chan, 2015) } \\
\hline \multicolumn{5}{|c|}{ To what extent do you agree with the following statements: $(1=$ Strongly agree, $7=$ Strongly disagree $)$} \\
\hline \multirow{3}{*}{$\begin{array}{l}\text { Information } \\
\text { sharing }(\mathrm{G}-\mathrm{INF})\end{array}$} & G-INF1 & $\begin{array}{l}\text { Social media is convenient for informing all my friends about my } \\
\text { ongoing activities }\end{array}$ & 3,12 & 1,63 \\
\hline & G-INF2 & $\begin{array}{l}\text { Social media allows me to save time when I want to share something } \\
\text { new with my friends }\end{array}$ & 3,03 & 1,62 \\
\hline & G-INF3 & I find social media efficient in sharing information with my friends & 2,85 & 1,59 \\
\hline \multirow{3}{*}{$\begin{array}{l}\text { New Relationship } \\
\text { Building (G- } \\
\text { SOC) }\end{array}$} & G-SOC1 & $\begin{array}{l}\text { Through social media I get connected to new people who share my } \\
\text { interests }\end{array}$ & 3,45 & 1,67 \\
\hline & G-SOC2 & Social media helps me to expand my network & 3,36 & 1,62 \\
\hline & G-SOC3 & I get to know new people through social media & 3,76 & 1,73 \\
\hline \multirow{3}{*}{$\begin{array}{l}\text { Self-presentation } \\
(\mathrm{G}-\mathrm{SP})\end{array}$} & G-SP1 & I try to make a good impression on others on social media & 3,13 & 1,51 \\
\hline & G-SP2 & I try to present myself in a favorable way on social media & 2,81 & 1,42 \\
\hline & G-SP3 & Social media helps me to present my best sides to others & 3,54 & 1,56 \\
\hline \multirow{3}{*}{$\begin{array}{l}\text { Enjoyment (G- } \\
\text { Ent) }\end{array}$} & G-Ent1 & When I am bored I often go to social media & 2,97 & 1,80 \\
\hline & G-Ent2 & I find social media entertaining & 2,81 & 1,48 \\
\hline & G-Ent-3 & I spend enjoyable and relaxing time on social media & 3,16 & 1,55 \\
\hline
\end{tabular}




\begin{tabular}{|c|c|c|c|c|}
\hline \multicolumn{3}{|c|}{ Concerns for Information Privacy (Smith, Milberg, \& Burke, 1996; Osatuyi, 2015) } & & \\
\hline \multicolumn{5}{|c|}{ To what extent do you agree with the following statements $(1=$ Strongly agree, $7=$ Strongly disagree $)$} \\
\hline \multirow{3}{*}{ Errors (ERR) } & ERR1 & $\begin{array}{l}\text { Social media sites should take more steps to make sure that personal } \\
\text { information in their database is accurate }\end{array}$ & 2,31 & 1,39 \\
\hline & ERR2 & $\begin{array}{l}\text { Social media sites should have better procedures to correct errors in } \\
\text { personal information }\end{array}$ & 2,43 & 1,36 \\
\hline & ERR3 & $\begin{array}{l}\text { Social media sites should devote more time and effort to verifying the } \\
\text { accuracy of the personal information in their databases before using it } \\
\text { for recommendations }\end{array}$ & 2,47 & 1,42 \\
\hline \multirow{4}{*}{ Collection (COL) } & COL1 & $\begin{array}{l}\text { It usually bothers me when social media sites ask me for personal } \\
\text { information }\end{array}$ & 2,42 & 1,37 \\
\hline & COL2 & $\begin{array}{l}\text { It usually bothers me when social media sites ask me for my current } \\
\text { location information }\end{array}$ & 2,42 & 1,43 \\
\hline & COL3 & $\begin{array}{l}\text { It bothers me to give personal information to so many people on } \\
\text { social media }\end{array}$ & 2,52 & 1,45 \\
\hline & COL4 & $\begin{array}{l}\text { I am concerned that social media sites are collecting too much } \\
\text { personal information about me }\end{array}$ & 2,53 & 1,39 \\
\hline \multirow{3}{*}{$\begin{array}{l}\text { Unauthorized } \\
\text { access (UAC) }\end{array}$} & UAC1 & $\begin{array}{l}\text { Databases that contain personal information should be protected from } \\
\text { unauthorized access - no matter how much it costs }\end{array}$ & 1,75 & 1,10 \\
\hline & UAC2 & $\begin{array}{l}\text { Social media sites should take more steps to make sure that } \\
\text { unauthorized people cannot access personal information on their site }\end{array}$ & 1,71 & 1,07 \\
\hline & UAC3 & Databases that contain personal information should be highly secured & 1,54 & 0,99 \\
\hline \multirow{3}{*}{$\begin{array}{l}\text { Secondary use } \\
\text { (SUS) }\end{array}$} & SUS1 & $\begin{array}{l}\text { Social media sites should not use personal information for any } \\
\text { purpose unless it has been authorized by the individuals who provide } \\
\text { the information }\end{array}$ & 1,65 & 1,05 \\
\hline & SUS2 & $\begin{array}{l}\text { When people give personal information to social media sites for some } \\
\text { reason, these sites should never use the information for any other } \\
\text { purpose }\end{array}$ & 1,85 & 1,19 \\
\hline & SUS3 & $\begin{array}{l}\text { Social media sites should never share personal information with third- } \\
\text { party entities unless authorized by the individual who provided the } \\
\text { information }\end{array}$ & 1,58 & 1,07 \\
\hline \multicolumn{5}{|c|}{ Marketing comfort (newly developed for this study) } \\
\hline \multicolumn{5}{|c|}{$\begin{array}{l}\text { How comfortable would you be if information about you or posted by you publicly on social media is } \\
\text { used for } \ldots ?(1=\text { Extremely comfortable, } 7 \text { = Extremely uncomfortable })\end{array}$} \\
\hline \multirow{3}{*}{$\begin{array}{l}\text { Marketing } \\
\text { comfort (MC) }\end{array}$} & MCAD & Targeted advertising & 4,69 & 1,79 \\
\hline & MCCR & Customer relations & 4,30 & 1,86 \\
\hline & MCOM & Opinion mining about products or services & 4,25 & 1,85 \\
\hline
\end{tabular}


Appendix 2: Internal reliability assessment: Outer loadings and weights (CFSMIP, SD and GRAT defined reflective-formative). In bold, indicator weights.

\begin{tabular}{|c|c|c|c|c|c|c|c|c|c|c|c|c|c|}
\hline & COL & ERR & SUS & UAC & SDAc & SDAD & SDI & SDPN & G-INF & G-SOC & G-SP & G-Ent & MKC \\
\hline COL1 & 0.81 & & & & & & & & & & & & \\
\hline COL2 & 0.78 & & & & & & & & & & & & \\
\hline COL3 & 0.82 & & & & & & & & & & & & \\
\hline COL4 & 0.82 & & & & & & & & & & & & \\
\hline ERR1 & & 0.88 & & & & & & & & & & & \\
\hline ERR2 & & 0.87 & & & & & & & & & & & \\
\hline ERR3 & & 0.87 & & & & & & & & & & & \\
\hline SUS1 & & & 0.89 & & & & & & & & & & \\
\hline SUS2 & & & 0.82 & & & & & & & & & & \\
\hline SUS3 & & & 0.88 & & & & & & & & & & \\
\hline UAC1 & & & & 0.85 & & & & & & & & & \\
\hline UAC2 & & & & 0.88 & & & & & & & & & \\
\hline UAC3 & & & & 0.86 & & & & & & & & & \\
\hline SDAc1 & & & & & 0.86 & & & & & & & & \\
\hline SDAc2 & & & & & 0.83 & & & & & & & & \\
\hline SDAc3 & & & & & 0.76 & & & & & & & & \\
\hline SDAc4 & & & & & 0.85 & & & & & & & & \\
\hline SDAD1 & & & & & & 0.83 & & & & & & & \\
\hline SDAD2 & & & & & & 0.86 & & & & & & & \\
\hline SDAD3 & & & & & & 0.73 & & & & & & & \\
\hline SDAD4 & & & & & & 0.78 & & & & & & & \\
\hline SDAD5 & & & & & & 0.82 & & & & & & & \\
\hline SDAD6 & & & & & & 0.78 & & & & & & & \\
\hline SDI1 & & & & & & & 0.84 & & & & & & \\
\hline SDI2 & & & & & & & 0.81 & & & & & & \\
\hline SDI3 & & & & & & & 0.81 & & & & & & \\
\hline SDP1 & & & & & & & & 0.84 & & & & & \\
\hline SDP2 & & & & & & & & 0.81 & & & & & \\
\hline SDP3 & & & & & & & & 0.79 & & & & & \\
\hline G-INF1 & & & & & & & & & 0.88 & & & & \\
\hline G-INF2 & & & & & & & & & 0.91 & & & & \\
\hline G-INF3 & & & & & & & & & 0.92 & & & & \\
\hline G-SOC1 & & & & & & & & & & 0.89 & & & \\
\hline G-SOC2 & & & & & & & & & & 0.83 & & & \\
\hline G-SOC3 & & & & & & & & & & 0.88 & & & \\
\hline G-SP1 & & & & & & & & & & & 0.89 & & \\
\hline G-SP2 & & & & & & & & & & & 0.88 & & \\
\hline G-SP3 & & & & & & & & & & & 0.86 & & \\
\hline G-ENT1 & & & & & & & & & & & & 0.85 & \\
\hline G-ENT2 & & & & & & & & & & & & 0.91 & \\
\hline G-ENT3 & & & & & & & & & & & & 0.91 & \\
\hline MKC1 & & & & & & & & & & & & & 0.56 \\
\hline MKC2 & & & & & & & & & & & & & 0.35 \\
\hline MCK3 & & & & & & & & & & & & & 0.22 \\
\hline
\end{tabular}


Appendix 3: Internal reliability and convergent validity assessment: Outer loadings and weights (CFSMIP, SD and GRAT defined reflective-formative). In bold, indicator weights.

\begin{tabular}{lccc}
\hline \multicolumn{3}{l}{ Construct reliability and convergent validity } & \\
\hline & $\alpha$ & $\rho_{c}$ & AVE \\
\cline { 2 - 4 } COL & 0.82 & 0.88 & 0.66 \\
ERR & 0.85 & 0.91 & 0.76 \\
SUS & 0.83 & 0.90 & 0.75 \\
UAC & 0.83 & 0.90 & 0.74 \\
SDAc & 0.84 & 0.89 & 0.68 \\
SDAD & 0.89 & 0.92 & 0.64 \\
SDPN & 0.74 & 0.85 & 0.66 \\
SDI & 0.76 & 0.86 & 0.68 \\
G-INF & 0.89 & 0.93 & 0.81 \\
G-SOC & 0.84 & 0.90 & 0.75 \\
G-SP & 0.85 & 0.91 & 0.77 \\
G-ENT & 0.87 & 0.92 & 0.80 \\
MKC & - & - & -
\end{tabular}

